\title{
Various demand side management techniques and its role in smart grid-the state of art
}

\author{
Muthuselvi Gomathinayagam, Saravanan Balasubramanian \\ School of Electrical Engineering, Vellore Institute of Technology, Vellore, India
}

\begin{abstract}
Article Info
Article history:

Received Feb 22, 2021

Revised Jul 16, 2021

Accepted Aug 7, 2021

\section{Keywords:}

Demand responses

Demand side management

Load forecasting

Smart grid

ABSTRACT

The current lifestyle of humanity relies heavily on energy consumption, thus rendering it an inevitable need. An ever-increasing demand for energy has resulted from the increasing population. Most of this demand is met by the traditional sources that continuously deplete and raise significant environmental issues. The existing power structure of developing nations is aging, unstable, and unfeasible, further prolonging the problem. The existing electricity grid is unstable, vulnerable to blackouts and disruption, has high transmission losses, low quality of power, insufficient electricity supply, and discourages distributed energy sources from being incorporated. Mitigating these problems requires a complete redesign of the system of power distribution. The modernization of the electric grid, i.e., the smart grid, is an emerging combination of different technologies designed to bring about the electrical power grid that is changing dramatically. Demand side management (DSM) allow customers to be more involved in contributors to the power systems to achieve system goals by scheduling their shiftable load. Effective DSM systems require the participation of customers in the system that can be done in a fair system. This paper focuses primarily on techniques of DSM and demand responses (DR), including scheduling approaches and strategies for optimal savings.
\end{abstract}

This is an open access article under the $\underline{C C B Y-S A}$ license.

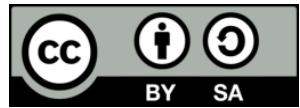

\section{Corresponding Author:}

Saravanan Balasubramanian

School of Electrical Engineering, Vellore Institute of Technology

Vellore-632014, Tamilnadu, India

Email: bsaravanan@vit.ac.in

\section{INTRODUCTION}

As society advances, energy demand is rising at an exponential rate. The traditional grid system is transformed into a new smart grid system with intelligent metering, intelligent sensors, and wireless communications in the generation, transmission, and distribution environments. Successful grid management in a smart grid is also essential to mitigate production costs and environmental hazards. Smart grids are defined as an electricity grid capable of intelligently integrating the activities of all consumer-related users, generators, and those who supply electricity efficiently in a sustainable, economical and safe way [1]. The grid data show exponential growth, and they are broad and involved with the advancement of sensor technology and advanced metering infrastructure (AMI).

Load forecasting can analyze and extract data through load data and other related data from internal factors and forecast load data for the next moment. Furthermore, the grid's efficiency can be more reliable and cost-efficient via the demand side management (DSM) and load factor. The smart grid can deal with current challenges in the present electricity system like capability, performance, reliability, sustainability, and client interaction from a global point of view [2]. By improving efficiency, electricity production can be 
improved. Another significant challenge is reliability. Distribution system problems cause most system failures that result in losses [3].

Smart grid also focuses on sustainability, in which key elements are the relationship of renewable energy and how it is handled to meet the requirement. Finally, the commitment of residential customers would allow DSM to reduce peak load, lower capability, cost, and increase overall performance. System losses and deployment of assets are two critical elements in considering performance [4]. Losses also rely on the system's load type. When investing in system infrastructure, the use of the system is an essential consideration. When considering the total system performance, optimum preparation for implementing the system assets and their usage plays a vital role. Smart grid innovations focus predominantly on development on the power management side [5]. The main aim of this paper is to outline the DSM technology that focuses on the demand responses (DR) program and user interaction.

\section{REVIEW ON DSM}

DSM applies both to the reduction in the electricity demand as well as to reduce congestion peaks [6]. As a consequence, it alters the pattern of time and the degree of the load. It is often more appropriate to adopt the generation pattern rather than flattening the curve [7]. Reliable power grid service depends primarily on the right balance between supply and load. It is not easy to maintain the balance between the consumer and the utility side [8]. It becomes much more challenging with the increase of distributed energy generation. It is not usually easy to follow the particular load curve by modulating fluctuating renewable energy sources.

The alternative is to use new technologies and methods, especially those based on user involvement. In conclusion, the traditional approach provides all the demands required whenever they happen. The new strategy says that users should also control the need to respond to current system conditions. The goal is to alter the load profile during peak hours using different attractive schemes by meeting the overall requirements. DR is the method of changing the load profiles of consumers with the help of additional incentives or cost-saving systems [9]. The basic idea of DR is a mutual understanding among service providers and consumers [10].

DSM has an essential scope further to increase the reliability and use of system properties. The number of resources required to satisfy present demand can be decreased using available power generation methods and the load factor significantly increased. The willingness to charge clients on the actual energy price is also a catalyst for the distribution system's modernization. Fixed tariffs on energy are pretty outdated and offer inter-client subsidies. The user should not be encouraged to contribute to the system's efficacy. If real-time pricing is introduced, the price will become elastic on the demand side instead of the fixed price tariff [11]. From the other direction, the supply curve would also be reshaped by an increased number of renewables. Overall, demand response strategies will allow customers to invest in both saving money and being more eco-friendly.

\subsection{DR techniques in DSM}

DR is a particular policy to encourage the consumers to respond by adjusting their usual energy use habits to changes in the tariff or timely based electricity availability. When grid stability is compromised, it can also be described as an incentive-based payment scheme to reduce electricity usage. In response, there are actionable items a user can take. Only during critical peak hours can customers minimize loads and retain regular load patterns during off-peak times. It triggers a reduction in the convenience of consumers as they are forced to limit the use of electricity at some times but decreases the total demand, further reducing the electricity bill. For responding to the high prices of electricity or low supply, a second step should be taken to mitigate electricity usage from peak to off-peak period. This approach would reduce the usage of appliances during peak periods and filling valleys of low consumption. The total energy consumption by end-users is not decreased, but the transmission and distribution efficiency is increased because of the robust system. Finally, on-site generation can be used by users to decrease demand according to the utility. It will improve consumer control, further decentralize generation, and reduce the distribution and transmission grid average load. Deferral load appliances are required to achieve load shaping. It is recommended that all residential loads be divided into wet, cold, water, and heating. These devices behave differently. These devices can be classified as thermal and static appliances that can be relocated.

Electricity consumption for heating is also expected to increase dramatically, giving DSM more space to optimize performance. The DR is typically carried out through peak clipping, peak load-shifting operations, or any mixture of the above methods. Because of the versatility demonstrated by the processes, DR is also recognized as a form of flexible load. It involves a program of flexible load adjustment that seeks to control energy management actions. DR programs are further categorized into DR programs that are either reliability-based or market-based. Consumers minimize their loads in reliability-based DR programs and 
participate in controlled appliance usage voluntarily or involuntarily. Besides, by enrolling in this initiative, customers derive economic benefits. By offering market rates for real-time energy, market-based DR services provide customers with choices for adjusting electricity use. Energy efficiency is characterized as a long-term process for energy savings and energy-efficient processes for reducing demand. DR strategies can further be characterized as incentive-based and price-based programs. The consumer is engaged in peak demand control using the classical incentive-based program by accepting to either shift their loads or to reduce their energy consumption. According to the terms and conditions of the program, the agreed consumers would face penalties while violating the conditions. Market-based systems will encourage users to engage in different incentive-based approaches to bid for load reduction and electricity procurement, and emergency DR.

Increased electrical energy load is defined as growth in strategic loads and is usually caused by storage and heating devices. Strategic energy growth is often inevitable due to the general rise in electricity demand, particularly with modern power systems for electric vehicles. Price-based schemes would use dynamic electricity pricing rates, representing electricity costs and availability in real-time. Time of use (TOU) is the simplest form of a price-based DR program. Since it involves the least supporting technology, it is already widely deployed. High peak pricing can be used to eliminate peaks during ON peak conditions. Real-time pricing (RTP) is one of the dynamic forms to shape the end-use load, and it monitors price in realtime. About the analysis of various DR programs in [12]. The most promising DR strategy is real time pricing. It adheres to traditional economic principles. It does not explicitly restrict the user from using other incentive-based systems, so users still choose load patterns.

From both technological and environmental perspectives, the response to demand is brutal. To provide two-way communication between users and utilities to transmit price signals, and bid data, most of the DSM techniques need a secure and high bandwidth link. DR also uses hardware-intensive-based approaches [13]. In order to respond on time without human intervention, there is a need for home energy management units and smart appliances for the participating consumers. Both customers and utilities will be supported by DSM and DR and make the overall structure highly stable and maximize social security. The merits and demerits of various DR techniques are summarized in Table 1.

Table 1. Various category of DR techniques

\begin{tabular}{|c|c|c|c|c|}
\hline $\begin{array}{l}\text { Residential } \\
\text { DR Scheme }\end{array}$ & Type & Response & Advantages & Disadvantages \\
\hline $\begin{array}{l}\text { Critical-peak } \\
\text { pricing } \\
(\mathrm{CPP})[15]\end{array}$ & Price based & Customer & $\begin{array}{l}\text { It depends on the peak load time. } \\
\text { Immediate incentive response }\end{array}$ & $\begin{array}{l}\text { Peak load shifting/Curtailing may occur } \\
\text { at the consumer end. } \\
\text { Not consider total energy consumption } \\
\text { cost. }\end{array}$ \\
\hline $\begin{array}{l}\text { Real-time } \\
\text { pricing } \\
\text { (RTP) [16] }\end{array}$ & Price based & Customer & $\begin{array}{l}\text { Electricity rates change daily/monthly on } \\
\text { an ongoing basis. } \\
\text { Most efficient scheme. }\end{array}$ & $\begin{array}{l}\text { Consumers are more aware of the } \\
\text { response to the DR program. }\end{array}$ \\
\hline $\begin{array}{l}\text { Direct load } \\
\text { control } \\
\text { (DLC) }[17]\end{array}$ & $\begin{array}{l}\text { Incentive- } \\
\text { based }\end{array}$ & Utility & $\begin{array}{l}\text { The utility provides incentives for shifting } \\
\text { /curtailing loads }\end{array}$ & $\begin{array}{c}\text { Customers load control authority for } \\
\text { some loads should be given to utility for } \\
\text { load balancing. }\end{array}$ \\
\hline $\begin{array}{c}\text { Emergency } \\
{[19]}\end{array}$ & $\begin{array}{l}\text { Incentive- } \\
\text { based }\end{array}$ & Utility & $\begin{array}{l}\text { The utility provides incentives/bonus for } \\
\text { shifting/curtailing loads }\end{array}$ & $\begin{array}{l}\text { The residential customer should } \\
\text { shift/curtail load for a particular time. }\end{array}$ \\
\hline
\end{tabular}

DSM is an evolving technique of dynamic resource management that has the dual effect of reducing energy consumption and facilitating effective and flexible system management. Highly blended renewable energy systems [20] are even less highly probable than traditional techniques of fossil-fuel generators alone to meet market demands. In this sense, DSM can be beneficial because it lowers electricity consumption by renewable energy sources during peak periods and less power generation. The DSM is an alternative way to increase the versatility of the new nuclear power plants introduced. An approach to maximizing the harmony between DSM and the versatility offered in a hybrid system by incredibly quickly generating units has been investigated.

The impacts of DSM were analyzed concerning effects such as economic, technological, and market-based impacts. DSM's overall services include; i) energy resource balancing, ii) retaining the 
reliability of electrical power systems, iii) avoiding initial costs, iv) improving productivity, v) minimizing operating costs, vi) increasing reliability and power factor, vii) increasing customer loyalty, and viii) improving system performance.

\section{LOAD MANAGEMENT PARADIGMS}

The energy utilities have evolved various load management techniques for this scope, categorized as local control, direct control, and distributed control. Notice that all of them need access to information from utilities in real-time, computer-based inside-house intelligence, home automation, appliances, and networks that can reduce their energy consumption. Local control consists of voluntary consumer collaboration to reduce load peaks by taking various energy tariffs into account, depending on the day. Therefore, in peak-off pricing season, consumers with heavy and not urgent power-consuming operations can switch them. Appliances-forced remote switching is based on direct control. The customers allow the utilities to install some remote-controlled switches in their homes after receiving financial inducement, which would monitor the load when required by disconnecting selected appliances.

Decentralized control is a mixed strategy that depends on the cooperation and coordination of consumers with utilities. The utility can change the electricity price in real-time according to the energy demand and the state of the grid load, while the consumer is called upon to adjust its consumption based on tariff rates. Home automation plays a fundamental role in this situation. For example, a device such as a dishwasher linked to the home energy management (HEM) may provide the consumer with the option to run the cycle when requested or to move it with an economic advantage for a certain period.

\section{VARIOUS APPROACHES IN DSM TECHNIQUES}

Chakraborty et al. [21] proposed efficient load scheduling-based DSM schemes to reduce the peak load. To minimize the peak value, G-MinPeak, and level-match algorithms based on the two-dimensional strip packing problem are used. Logenthiran and Srinivasan [22] suggested a heuristic optimization for peak load management in DSM using the shifting technique. The research aims to minimize the gap between the final load curve and the ideal objective curve.

A novel energy management framework is being developed to improve the performance of renewable energy and storage systems by planning numerous household appliances [23]. End users schedule the devices optimally, taking into account both the overall benefit and the minimum energy expense of the user as strategic goals. The unknown approximation model is translated by applying the theory of probability into a combinatorial optimization problem. A quasi-newton approach is used to obtain the optimum solution.

Game theory is one of the fundamental principles used in [24] to schedule residential energy usage. An optimization-based decentralized distributed algorithm is implemented in this article. Many aspects of scheduling for energy utilization are thoroughly studied. The authors considered a pricing model based on a convex and rising cost function. This research is seen as a reference to strategies for enhancing DSM.

Users are offered rewards to enable them to prepare their loads effectively. If the utility providers have pricing details a few hours before consumption time, this is true. The Energy consumption scheduling unit must also forecast prices in real-time electricity pricing environments to monitor load.

A DSM focused on heuristic optimization is adopted based on the evolutionary algorithm model in [25]. As a minimization problem, known as the day-ahead pricing scheme, a modern pricing scheme is also mathematically used. The proposed approach is analyzed for all the customers, like domestic, industrial, and commercial types. In that scheduling-based optimization model, it was realized that the waiting time of devices is inversely related to appliance delay time. The influence of their suggested work is global. Their suggested billing system prevents synchronizing loads. The results of the simulation show productivity by minimizing total peak-to-average power ratio (PAR), consumption cost, and fairness as well. Minimizing the waiting time for shiftable appliances plays a crucial role in encouraging consumer participation in the DR program. However, it is not discussed in that article.

The authors develop an optimization problem based on game theory to reduce PAR, and total energy cost minimizations are explored in [26]. Antonopoulos et al. [26] suggested a new pricing scheme which is the combination of RTP with the TOU billing technique. Also analyzed the empirical case study and their coverage area for residential-style users are global. For DSM, the energy consumption scheduler is based on an artificial intelligence technique known as a backtracking algorithm. For residential-style users, the RTP mechanism is approved. PAR reduction and the time needed to execute the algorithm are the only problems that they have explored.

In achieving successful DSM, the model pricing strategy also plays a crucial role. Comprehensive mathematical modeling with price prediction capability is taken into consideration. Distributed scheduling is used for optimization in [27]. Heuristic and metaheuristic based optimization is used in [28], [29]. A filter- 
based weighted average price forecast and a combination of tilting block rates with real-time pricing are discussed [30]. Inside a smart meter, the price is predicting and energy scheduling mechanisms are considered. To demonstrate better results, distinct scenario performance parameters are clarified and simulated. The waiting time of the appliances is inversely related to the control parameter that is adjustable. The overall results are satisfying, but there is no discussion of the question of fairness. In the form of bonus payments, customers often gain economic benefits from engaging in different DSM systems based on game theory [31], [32]. On the utility side, these financial benefits are typically lower maintenance costs, lowered load losses, and improved performance of the system. Dynamic pricing algorithms [33], [34] used for flattening the demand curve in an efficient manner.

The effects of DSM mainly on the energy market model have been extensively investigated as well [35]. Comparison of various DSM techniques are summarized in Table 2. DR and economic dispatch have been integrated to increase machine efficiency. The merging of DSM and unit commitment leads to boost the electricity market's efficiency and reduce operating device costs. The time-of-use rate has been introduced on distribution systems with significant commercial and industrial loads to minimize utility and consumer costs simultaneously.

Table 2. Comparison of various DSM techniques

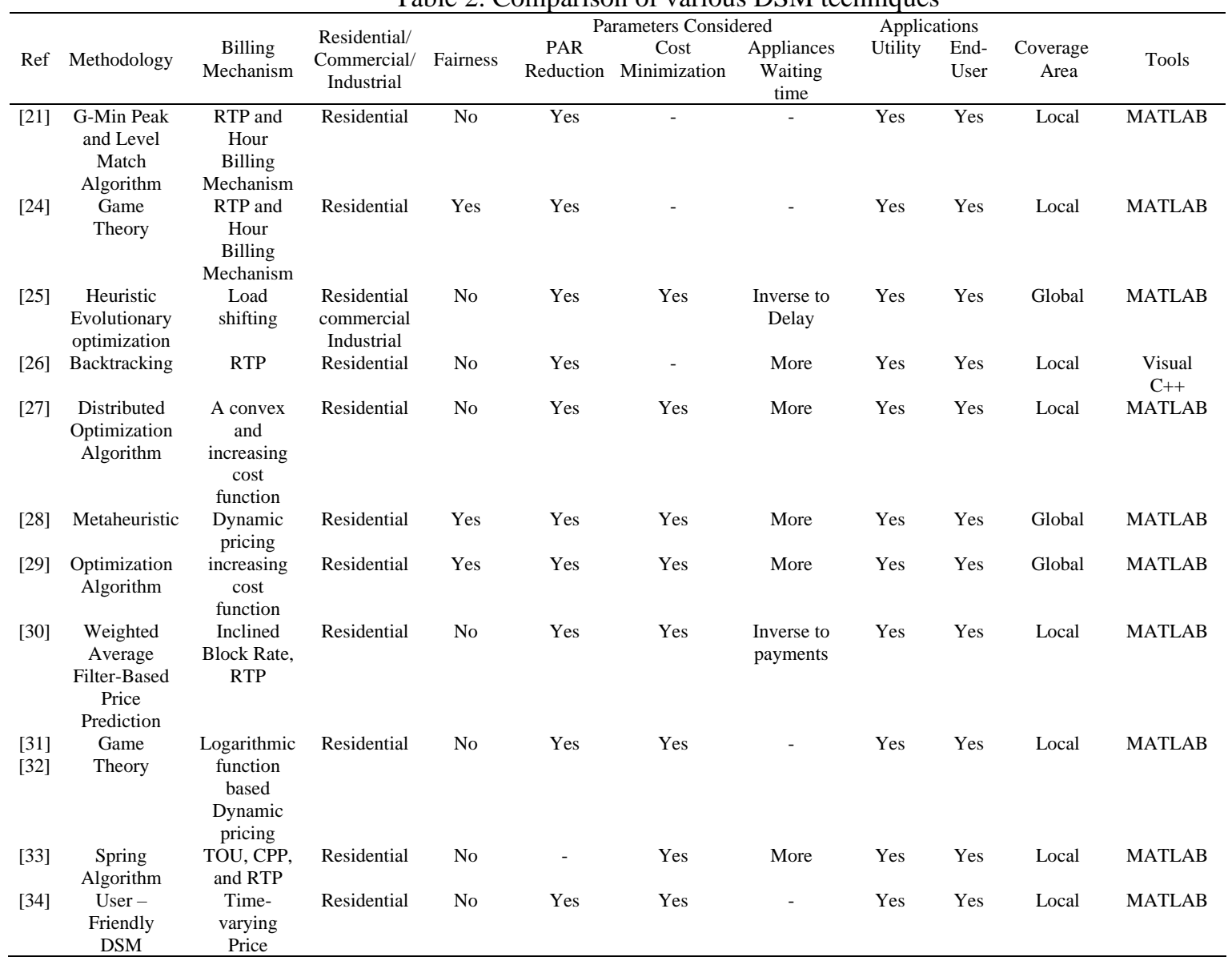

\section{CONCLUSION}

DSM enables the power system to retain system efficiency, costs and reliability within the necessary demands and limits. It offers an effective solution to peak demand and significantly enhances the system's reliability. Therefore, it is a versatile method of the future management of the smart grid. The basis of the analysis is the fiscal, ecological, market-wide, and technological effects of the DSM. The potential benefits of introducing DSM into smart grids are also presented in this paper. This article presented a study of the state of the art of DSM in smart grids. Also overviewed the understanding of the research gaps in demand side management from classification to control techniques. 


\section{REFERENCES}

[1] S. A. Mansouri, M. S. Javadi, A. Ahmarinejad, E. Nematbakhsh, A. Zare, and J. P. S. Catalão, "A coordinated energy management framework for industrial, residential and commercial energy hubs considering demand response programs," Sustainable Energy Technologies and Assessments, vol. 47, pp. 1-18, 2021, Art no. 101376, doi: 10.1016/j.seta.2021.101376.

[2] R. Kappagantu and S. A. Daniel, "Challenges and issues of smart grid implementation: A case of Indian scenario," Journal of Electrical Systems and Information Technology, vol. 5, no. 3, pp. 453-467, 2018, doi: 10.1016/j.jesit.2018.01.002.

[3] N. Tleis, "Power systems modelling, and fault analysis," Second Edition, Academic Press, pp. 1-39, 2019.

[4] G. Muthuselvi and B. Saravanan, "The promise of DSM in smart grid using home energy management system with renewable integration," 2017 Innovations in Power and Advanced Computing Technologies (i-PACT), 2017, pp. 1-4, doi: 10.1109/IPACT.2017.8245102.

[5] O. M. Butt, M. Zulqarnain, and T. M. Butt, "Recent advancement in smart grid technology: Future prospects in the electrical power network," Ain Shams Engineering Journal, 2020, doi: 10.1016/j.asej.2020.05.004.

[6] S. Li, J. Yang, W. Song, and A. Chen, "A real-time electricity scheduling for residential home energy management," IEEE Internet of Things journal, vol. 6, pp. 2602-2611, 2019, doi: 10.1109/JIOT.2018.2872463.

[7] G. Dutta and K. Mitra, "A literature review on dynamic pricing of electricity," Journal of Operational Research, vol. 68, pp. 1131-1145, 2017.

[8] H. Safiullah, G. Hug, and R. Tongia, "Design of load balancing mechanism for Indian electricity markets," Energy System, vol. 8, pp. 309-350, 2017, doi: 10.1007/s12667-016-0199-3.

[9] G. H. Philipo, Y. A. C. Jande, and T. Kivevele, "Demand side management of solar microgrid operation: effect of time-of-use pricing and incentives," Journal of Renewable Energy, vol. 2020, pp. 1-12, 2020, doi: 10.1155/2020/6956214.

[10] S. O. Muhanji, A. E. Flint, and A. M. Farid, "Transactive energy applications of eIoT," eIoT, pp. 91-113, 2019, doi: 10.1007/9783-030-10427-6_4.

[11] J. Andruszkiewicz, J. Lorenc, and A. Weychan, "Demand price elasticity of residential electricity consumers with zonal tariff settlement based on their load profiles," Energies, vol. 12, pp. 1-22, 2019, doi: 10.3390/en12224317.

[12] S. Phommixay, M. L. Doumbia, and D. L. St-Pierre, "Review on the cost optimization of microgrids via particle swarm optimization," International Journal of Energy Environmental Engineering, vol. 11, pp. 73-89, 2020, doi: 10.1007/s40095-01900332-1.

[13] M. S. Mahmoud, "Microgrid control problems and related issues," Microgrid-Advanced Control Methods and Renewable Energy System Integration, vol. 1, pp. 1-42, 2017

[14] F. Luo, W. Kong, G. Ranzi, and Z. Y. Dong, "Optimal home energy management system with demand charge tariff and appliance operational dependencies," IEEE Transactions on Smart Grid, vol. 11, pp. 4-14, 2020, doi: 10.1109/TSG.2019.2915679.

[15] D. Thomas, G. D'Hoop, O. Deblecker, K. N. Genikomsakis, and C. Loakimidis, "An integrated tool for optimal energy scheduling and power quality improvement of a microgrid under multiple demand response schemes," Applied Energy, vol. 260, pp. 1-16, 2020, doi: 10.1016/j.apenergy.2019.114314.

[16] M. V. Dahraie, H. Najafi, A. A. Moghaddam, and J. M. Guerrero, "Security constrained unit commitment in AC microgrids considering stochastic price-based demand response and renewable generation," International Transaction on Electrical Energy Systems, vol. 28, 2018

[17] T. Lio and G. Yan, "Real-time pricing for smart grid with distributed energy and storage: A non-cooperative game method considering spatially and temporally coupled constraints," International Journal of Electrical Power and Energy Systems, vol. 115, pp. 1-8, 2020, doi: 10.1016/j.ijepes.2019.105487.

[18] H. Zhu, Y. Gao, Y. Hou, and T. Li, "Multi-time slots real-time pricing strategy with power fluctuation caused by operating continuity of smart home appliances," Engineering Applications of Artificial Intelligence, vol. 71, pp. 166-174, 2018, doi: 10.1016/j.engappai.2018.02.010.

[19] P. Harsh and D. Das, "Energy management in microgrid using incentive-based demand response and reconfigured network considering uncertainties in renewable energy sources," Sustainable Energy Technologies and Assessments, vol. 46, 2021, Art no. 101225, doi: 10.1016/j.seta.2021.101225.

[20] V. Gutierrez-Martinez, C. A. Moreno-Bautista, J. M. Lozano-Garcia, A. Pizano-Martinez, E. Zamora-Cardenas, and M. GomezMartinez, "A heuristic home electric energy management system considering renewable energy availability," Energies, vol. 12, no. 4, 2019, Art. no. 671, doi: 10.3390/en12040671.

[21] N. Chakraborty, A. Mondal, and S. Mondal, "Efficient load control based demand side management schemes towards a smart energy grid system," Energies, vol. 59, 2020, doi: 10.1016/j.scs.2020.102175.

[22] T. Logenthiran, D. Srinivasan, and T. Z. Shun, "Demand side management in smart grid using heuristic optimization," IEEE Transactions on Smart Grid, vol. 3, no. 3, pp. 1244-1252, 2012, doi: 10.1109/TSG.2012.2195686.

[23] Z. Xu, Y. Gao, M. Hussain, and P. Cheng, "Demand side management for smart grid based on smart home appliances with renewable energy sources and an energy storage system," Mathematical Problems in Engineering, vol. 2020, pp. 1-20, 2020, doi: $10.1155 / 2020 / 9545439$.

[24] M. Pilz and L. Al-Fagih, "A dynamic game approach for demand-side management: scheduling energy storage with forecasting errors," Dynamics Games Application, vol. 10, pp. 897-929, 2020, doi: 10.1007/s13235-019-00309-z.

[25] C. Bharathi, D. Rekha, and V. Vijayakumar, "Genetic algorithm based demand side management for smart grid," Wireless Personal Communication, vol. 93, pp. 481-502, 2017, doi: 10.1007/s11277-017-3959-z.

[26] I. Antonopoulos et al., "Artificial intelligence, and machine learning approaches to energy demand-side response: A systematic review," Renewable and Sustainable Energy Reviews, vol. 130, pp. 1-35, 2020.

[27] M. Latifi, A. Khalili, A, Rastegarnia, S. Zandi, and W. Bazzi, "A distributed algorithm for demand-side management: Selling back to the grid," Heliyon, vol. 3, pp. 1-28, 2017, doi: 10.1016/j.heliyon.2017.e00457.

[28] D. Santra, A. Mukherjee, K. Sarker, and S. Mondal, "Dynamic economic dispatch using hybrid metaheuristics," J. of Electrical Systems and Information Technology, vol. 7, pp. 1-30, 2020, doi: 10.1186/s43067-020-0011-2.

[29] T. Luz, P. Moura, and A. De Almeida, "Multi-objective power generation expansion planning with high penetration of renewables," Energy Procedia, vol. 143, pp. 210-215, 2017.

[30] B. Sivaneasa, M. L. Lim, and K. P. Goh, "Overcoming solar PV intermittency using demand response management in buildings," Renewable and Sustainable Energy Reviews, vol. 81, pp. 2637-2643, 2018

[31] D. Srinivasan, S. Rajgarhia, B. M. Radhakrishnan, A. Sharma, and H. P. Khincha, "Game-theory based dynamic pricing strategies for demand side management in smart grids," Energy, vol. 126, pp. 132-143, 2017, doi: 10.1016/j.energy.2016.11.142.

[32] R. Lu, S. H. Hong, and X. Zhang, "A Dynamic pricing demand response algorithm for smart grid: reinforcement learning approach," Applied Energy, vol. 220, pp. 220-230, 2018, doi: 10.1016/j.apenergy.2018.03.072. 
[33] T. C. Chiu, Y. Shih, A. Pang, and C. Pai, "Optimized day-ahead pricing with renewable energy demand-side management for smart grids," IEEE Internet of Things journal, vol. 4, no. 2, pp. 374-383, 2017, doi: 10.1109/JIOT.2016.2556006.

[34] Z. Irshad, S. M. H. Aejaz, U. Mustafa, A. M. F. Durrani, and F. Hafeez, "User-friendly demand side management for smart grid network," 2020 International Conference on Engineering and Emerging Technologies, 2020, pp. 1-12, doi: 10.1109/ICEET48479.2020.9048212.

[35] G. Dileep, "A survey on smart grid technologies and applications," Renewable Energy, vol. 146, pp. 2589-2625, 2020, doi: 10.1016/j.renene.2019.08.092.

\section{BIOGRAPHIES OF AUTHORS}

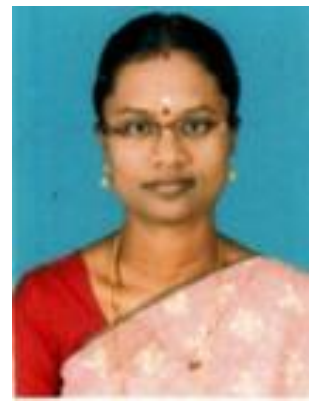

Muthuselvi Gomathinayagam (D) $S \mathrm{SC}$ P is a research scholar doing her Ph.D. in the School of Electrical Engineering at Vellore Institute of Technology. Her research interest includes smart grid, demand side management, residential energy management, and renewable energy sources. She can be contacted at email: gtecmuthuselvi@gmail.com

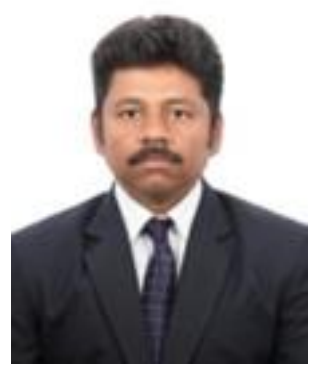

Saravanan Balasubramanian (D) SC $\mathrm{P}$ is currently working as Associate Professor in the School of Electrical Engineering at Vellore Institute of Technology. He has published more than 47 papers in reputed journals. His research interest includes power system optimization, unit commitment, energy management system and grid integration of renewable energies. He can be contacted at email: bsaravanan@vit.ac.in 